Session 2275

\title{
A Process to Earn Promotion and Tenure
}

\author{
By John R. Williams, Dr. Martin Pike \\ Purdue University
}

\begin{abstract}
$\underline{\text { Abstract }}$
Before a new business is created or an existing business will expand to gain financial backing from others, the first thing that banks and other capital sources usually want to see is the business plan for the company. This plan is a detailed plan that includes an assessment of the business' finances, market, suppliers, strengths and weaknesses. This plan provides a realistic set of goals for the business and a guide for future actions and decisions. The new faculty member is in much the same position as a business with one main difference. The business is the person. Just like businesses, for a faculty member to succeed in achieving goals, such as earning tenure and promotion, a strategic plan is necessary. A steady progression of achievement and growth are usually required to attain promotion and tenure. This progression and progress is guided by the strategic plan. This paper discusses the thoughts, advice and process of a tenure track faculty member in the past five years of work. Following will be a discussion of the importance of strategic planning to a new faculty member and how this type of planning could ease the load in attaining tenure and promotion.
\end{abstract}

\section{$\underline{\text { Part I - An Example }}$}

\section{$\underline{\text { Introduction }}$}

Transition from one walk of life to another is never easy. Whether one enters academia from industry, graduate school or from some other venue, significant differences exist which may hinder the progress of the new educator. In the present case, coming from industry, but with teaching experience as an adjunct, I thought I had an understanding of the teaching requirements. What to do about tenure was the farthest thing from my mind. Fortunately, I had the help of my co-author as mentor and the other staff at our site. They all helped me keep in the right direction to start with. Eventually, it was up to me to shape the direction that my tenure path would take, accompanied by the advice and guidance of my associates and my department head. Even so, the path has been difficult and the outcome is not yet decided.

\section{The Process}

In the Purdue University School of Technology, it is a given that all faculty will teach, and will teach well. Course development, laboratory development, finding new ways to present material, preparation of auxiliary educational materials as well as grading all occupy considerable effort. Faculty must keep current on new developments in their course areas. At the same time, faculty 
must be working in areas other than teaching, including Service, Research and Creative Endeavor to contribute to the science and art of education.

For new faculty, regardless of background, these elements present a formidable challenge. The following is something of a chronological sequence that was used by the author to phase into the system.

\section{First Year}

The other two professors in my department were extremely helpful in guiding my first faltering steps, helping me avoid pitfalls into which they had already plunged. It was absolutely necessary to focus on teaching the new courses which I was assigned. There was no experienced predecessor to call upon, only some notes and a few artifacts. Fortunately, two courses were being taught in two sections, so I was able to coordinate with the experienced associate and basically follow his lead.

Key lessons learned were that there is never enough time to do everything thoroughly. Tasks must be prioritized in terms of both importance and time frame. Tenure lessons were few the first year. The importance of attending meetings and conferences where teaching excellence is discussed became evident. It is here that other educators share their experiences in the hope of helping all excel in teaching.

\section{$\underline{\text { Second Year }}$}

The new faculty should now be more comfortable in the classroom, and have some grasp of the students that he or she must face. Class preparation should be easier, even if new courses are being taught, because of the experience of the first year's preparations. Faculty should make innovations to improve classroom presentations, laboratory exercises, etc., based upon the experience of the first year. What worked, what didn't, and why? One learns that student feedback from surveys can be very useful, if collected, read and acted upon. This step should not be limited to the formal faculty evaluation used in most institutions, but should include direct surveys, usually anonymously, in response to specific questions. I have successfully used a ranking method, such as evaluating the degree of agreement or disagreement with a statement, and the essay method, where a written answer is required. In the latter case, one can ask someone else to type the responses if there is any question that the faculty might try to identify who said what.

An additional feedback method is input from your associates. Sometimes, students will complain to one of your associates, who can then provide anonymous feedback to you. I encourage my students to complain to someone else if they fear retribution by direct discussion. At the same time, I find they are more encouraged to talk directly to me when they know they can go elsewhere if need be. This is particularly true when a student has been exposed to one or more of my other classes. 
Key lessons learned included the need to focus on two or three specific areas of teaching with respect to writing and presenting papers for educational conferences. There is so much good material being discussed that only high quality work will see the light of day. The major problem is finding time to focus and learning what to focus on.

$\underline{\text { Third and Fourth Years }}$

Once well established with the courses being taught, hard choices must be made in terms of how to focus on productive efforts, and eliminate worthwhile, but non-productive tasks. By "productive" we mean those tasks that will enhance the success of the tenure effort. In the teaching area, it is difficult to differentiate between the tasks that are expected of every teacher, and the tasks that yield beneficial results for tenure. The same dilemma occurs within the areas of Service, Research and Creative Endeavor.

\section{Fifth Year}

This is the time to polish off the effort, for most institutions. Sometimes, the department head and the committee will recommend moving forward one year early, particularly if the faculty member has taught for some years at other institutions. For the neophyte, this path could be fraught with peril, and should be taken only on the advice of competent counselors. This year before the penultimate year is when organization of activities pays off. What is missing in the tenure document? How can the deficiency be corrected quickly?

The major aspect of what was missing in the author's process is a coherent plan of action and set of goals to guide that action plan. The process would have been less stressful and more efficient had a strategic plan been design and used.

\section{$\underline{\text { Part II - Strategic Planning }}$}

There are three basic aspects to strategic planning that apply to a faculty is member attaining promotion and tenure. First is to determine the goals or outcomes of the overall and individual activities. Second, determine the activities that will lead to the successful attainment of the goals. Third, and possibly the most important, obtain department head and dean agreement with the plan. These three parts of strategic planning are intertwined but are necessary to be considered, planned and documented.

\section{$\underline{\text { Goals }}$}

The obvious overall goal for the new faculty member is to attain promotion and tenure. Attaining this overall goal is in reality the result of the successful attainment of a combination of activity based goals in the first few years of the academic career. Most colleges and universities have the triad conditions of proven accomplishment in research, teaching and service. The stress placed on and amount of activity that each aspect of the triad requires is a combination of institutional interests and individual interests and abilities. Therefore, it is important that the new faculty member do two things as soon as possible. First, the faculty member should assess his or her strengths, weaknesses, and interests within each of the triad areas. Second, the faculty member 
should question colleagues, the department head and if possible the dean to get their input as to the expectations and "job opening" in each of the triad areas. Using this information, the faculty member should formulate a set of goals for each area of research, teaching and service. These goals should be realistic, within the faculty members abilities, and form a progression of achievement. These goals serve as a guide for the activities in which to be involved. If an activity does not lead to the attainment of a goal, it is a waste of time and effort and therefore should not be done. The goals should be written down with achievement dates to serve as a reminder and check-off list.

\section{$\underline{\text { Action Plan }}$}

The second aspect of strategic planning is to determine the activities that will achieve the goals decided upon. Again, the self analysis and input from others is important here. The process outlined in Part I above showing a smooth progression of increasing responsibility, involvement and productivity is a good way to proceed. The first year or two should be an investment in laying a good foundation upon which to grow and improve. However, from the beginning, activities should be planned that lead to attaining some goals in the early years since delaying accomplishments in any area of the triad creates further delays and reduces the chance of attaining the overall goal.

A good action plan should include aspects of evaluation, as shown above, to be sure that things are improving and progressing. In addition, a good action plan should be aggressive but realistic. A mentor or other colleagues are good guides as to what can be expected to be accomplished within the time available. They also may help by direct assistance (co-author papers, team teach) or provide resources to make the job easier and better assure the goals are attained.

The action plan should be written as a reminder and check-off list. It will also serve as a basis for the document that many institutions require for the tenure and promotion process. Creating this document is much easier if all the activities and accomplishments are summarized in one place along with supporting documents. The action plan also helps in creating an annual evaluation report if the institution requires one. The action plan should be referred to on a regular basis to assess progress towards goals and to ensure that no aspect of the triad is ignored.

\section{$\underline{\text { Agreement and Implementation }}$}

Using the written goals and action plan, the new faculty member is ready for the last aspect of the strategic planning process. This is to get the approval of the department head and dean. This step serves three purposes. First, these people are the ones who will be evaluating the new faculty member's progress, recommending pay increases, and representing and being the advocate for the new faculty in the tenure and promotion process. The more these people know about the new faculty member and their work, the better advocate they can be. Secondly, if the head and dean know and approve of the plan, the better is the assurance of attaining the tenure and promotion goal because the new faculty and the institution are working together instead of working in opposite directions. Thirdly, the head and dean know of resources and opportunities that will assist the new faculty member within the institution, in professional societies and in other aspects 
of professional life. If they are knowledgeable of the faculty member's interests and talents, when something comes up that is a good match, they will approach the faculty member to get involved. Often more can be accomplished and better opportunities are available by being invited to participate than any other mechanism to get involved. Both authors owe significant portions of their accomplishments to being recommended or invited to participate in this manner.

\section{Conclusion}

Tenure and promotion is a long, often difficult, and daunting process. A strategic plan can help alleviate the stress associated with the process, serve as a guide and provide assistance to the new faculty member. A progression of activity helps the faculty member continue to accomplish relevant and useful work while building a case for tenure and promotion. A common thread throughout this planning process and the implementation process is the agreement and help of a mentor, colleagues, heads and deans. These people are helpful guides and assistants for the new faculty. The planning process is not a one time activity. Since people, institutions, and new faculty change and grow the plan should be periodically evaluated and updated. A good time for this is during the annual review with the department head.

John Williams is Assistant Professor of Mechanical Engineering Technology at Purdue University. He holds a B.S.M.E. degree from Rose Hulman Institute of Technology and an M.S.E. degree from Purdue University. He joined Purdue University after 34 years of service with the Allison Gas Turbine Division of General Motors. He is a Registered Professional Engineer in the State of Indiana and is a member of ASEE, and ASME.

MARTIN PIKE is an Associate Professor of Mechanical Engineering Technology at Purdue University at Kokomo. He has over thirteen years of teaching experience in addition to six years experience in industry as a design and development engineer. He earned a B.S.M.E. in 1977, an M.S.E. in 1981 and Dr. Sci. in Engineering in 1990. He is a Registered Professional Engineer in the Commonwealth of Pennsylvania and is a member of ASEE, and ASME. 